\title{
OJS OPEN

\section{DIÁLOGOS ENTRE SABERES DOCENTES E A FORMAÇÃO DO LICENCIADO EM GEOGRAFIA: CONTRIBUIÇÕES DO PIBID}

\author{
Raiany Priscila Paiva Medeiros Nonato ${ }^{1}$, Maria Juliana do Nascimento ${ }^{2}$, Mariana Pricilia de Assis ${ }^{3}$, \\ Cícero Nilton Moreira da Silva ${ }^{4}$
}

\begin{abstract}
${ }^{1}$ Geógrafa Licenciada e Mestra em Ensino. E-mail: raianypriscila18p@gmail.com - ORCID iD: http://orcid.org/00000001-7724-9320

${ }^{2}$ Geógrafa Licenciada. Mestranda pelo Programa de Pós-Graduação em Ensino (PPGE), da Universidade do Estado do Rio Grande do Norte (UERN), Campus Avançado de Pau dos Ferros (CAPF). E-mail: mjuhnascimento@gmail.com ORCID iD: http://orcid.org/0000-0003-0142-7009.

${ }^{3}$ Geógrafa Licenciada. Mestranda pelo Programa de Pós-Graduação em Ensino (PPGE), da Universidade do Estado do Rio Grande do Norte (UERN), Campus Avançado de Pau dos Ferros (CAPF). E-mail: maryeduca93@gmail.com ORCID iD: http://orcid.org/0000-0001-8104-6956.

${ }^{4}$ Professor Adjunto do Quadro Permanente do Curso de Licenciatura em Geografia e do corpo docente permanente do Programa de Pós-Graduação em Ensino (PPGE), ambos da Universidade do Estado do Rio Grande do Norte (UERN), Campus Avançado de Pau dos Ferros (CAPF). E-mail: ciceronilton@ yahoo.com.br - ORCID iD: http://orcid.org/00000001-6773-7451.
\end{abstract}

Artigo recebido em 11/08/2020 e aceito em 08/01/2021

\section{RESUMO}

Neste artigo, analisa-se a contribuição do Programa Institucional de Bolsa de Iniciação à Docência (PIBID) para a formação docente em Geografia. Fundamenta-se em uma abordagem qualitativa, combinando com a pesquisa do tipo bibliográfica e o uso de entrevistas, cujas análises tomam como referência a Análise de Conteúdo (AC). Constata-se, mediante dados construídos, que o Subprojeto PIBID Geografia tem fomentado o aperfeiçoamento da formação do licenciado em Geografia, através do protagonismo da ação docente, de diferentes maneiras, a saber: da vivência prolongada no ambiente escolar; da experiência com a construção de materiais didáticos-pedagógicos nas escolas, da construção e desenvolvimento de projetos, assim como no decorrer da socialização destas vivências nos ambientes acadêmico e escolar.

Palavras-chave: Saberes docentes; Formação de professores; PIBID; Subprojeto Geografia.

\section{DIALOGUES BETWEEN TEACHING KNOWLEDGE AND THE TRAINING OF THE LICENSED IN GEOGRAPHY: CONTRIBUTIONS FROM PIBID}

\section{ABSTRACT}

In this article, the contribution of the Institutional Teaching Initiation Scholarship Program (PIBID) to the teaching of Geography is analyzed. It is based on a qualitative approach, combining with bibliographic type research and the use of language, it presents analyzes based on Content Analysis (AC). It is verified, through constructed data, that the PIBID 
Geography Subproject has promoted the improvement of the education of the graduate in Geography, through the protagonist of the teaching action, in different ways: of prolonged experience in the school environment; from the experience with the construction of didactic-pedagogical materials in schools, from the construction and development of projects, as well as in the course of socializing these experiences in the academic and school environments.

Keywords: Teaching Knowledge; Teacher training; PIBID; Geography subproject.

\section{INTRODUÇÃO}

Este artigo tem como premissa analisar a contribuição do Programa Institucional de Bolsa de Iniciação à Docência (PIBID) na formação docente em Geografia. O referido programa possibilita ao graduando a integração teoria e prática no âmbito da escola. Isso porque é na prática do espaço escolar que se atribui sentido à teoria, de modo que, ao integrar a práxis, no cotidiano escolar, os saberes apreendidos na formação acadêmica passam a ser mais significativos.

O Subprojeto PIBID Geografia do Campus Avançado de Pau dos Ferros (CAPF), da Universidade do Estado do Rio Grande do Norte (UERN), trabalhou as ações descritas ao longo deste trabalho, no quadriênio 2014-2018, por intermédio de intervenções didático-pedagógicas em duas Escolas Estaduais, ambas sediadas em Pau dos Ferros/RN. O programa conta com uma equipe constituída por 01 (um) Professor Coordenador de área, 04 (quatro) professores supervisores escolares e 20 (vinte) licenciandos bolsistas.

Dentre as ações previstas no Subprojeto PIBID Geografia, os licenciandos bolsistas planejavam as atividades a serem realizadas, de acordo com o plano de trabalho do Subprojeto, sendo o supervisor de área escolar o responsável pelo acompanhamento e orientação destes, no cotidiano de sua aplicação nas duas unidades escolares parceiras. O professor supervisor possui função primordial, já que deve propiciar a dinâmica de esclarecer, para todo o grupo envolvido, as melhores estratégias de ações e intervenções a serem desenvolvidas na escola.

Além disso, as ações nas escolas eram acompanhadas, também, pelo Coordenador de área, por intermédio do diálogo com o Supervisor e das reuniões coletivas, nas quais ocorriam as avaliações e a síntese do registro do desenvolvimento das ações realizadas. Previamente, afirma-se que o trabalho desenvolvido objetivou aprimorar a formação inicial dos discentes do Curso de Geografia do CAPF/UERN, buscando, na prática, a construção do aprendizado da licenciatura.

É nesse contexto que o referente trabalho permeia sobre a óptica da significância da prática docente na formação do licenciando, a partir da experiência do PIBID, possibilitando a integração 
dos saberes acadêmicos com os saberes escolares, tornando-se um elemento preponderante para a formação docente.

Dessa maneira, o aporte teórico-metodológico, que serve de orientação às intervenções do Subprojeto PIBID Geografia, bem como à prática de pesquisas dos conteúdos a serem trabalhados em sala de aula, fundamenta-se em Cavalcanti (1999). Além disso, foram formulados os conteúdos desenvolvidos em oficinas didático-pedagógicas, com produção de material auxiliar ao processo ensino-aprendizagem, tais como: cartilhas, mural de cartazes, seminários temáticos, jogos pedagógicos, seguindo olhar metodológico de Pontuschka \& Oliveira (2006): utilizando os conteúdos abordados em sala de aula, além de aula de campo na comunidade do entorno da escola, e finalizando com evento de socialização das atividades do semestre.

Para a construção deste artigo, realiza-se uma pesquisa bibliográfica, recorrendo a autores que discutem a formação docente inicial e os saberes docentes, a exemplo de Pereira (1999), Pimenta (1999), Pires (2009) e Tardif (2011); destacando alguns itens previstos na portaria $\mathrm{n}^{\circ} 096$ de 18 de julho de 2013, oriunda do Ministério da Educação (MEC) e da Coordenação de Aperfeiçoamento de Pessoal de Nível Superior (CAPES); e descrevendo as ações contidas no Subprojeto PIBID Geografia do CAPF/UERN. Do ponto de vista dos instrumentos utilizados para a coleta dos dados empíricos, a técnica utilizada foi a entrevista semiestruturada, com questões abertas, com vistas a estabelecer uma aproximação com a concepção dos sujeitos que vivenciaram o programa de formação docente inicial no quadriênio 2014-2018.

Desse modo, os(as) colaboradores(as) desta pesquisa são 4 licenciados em Geografia, que atuaram como bolsistas do Subprojeto PIBID Geografia em duas escolas parceiras do programa, na cidade de Pau dos Ferros/RN. Após a realização das entrevistas, foi realizada a sistematização e análise dos dados construídos à luz do procedimento de Análise de Conteúdo (AC), por meio do qual definimos categorias analíticas para dar subsídio à interpretação da problemática estudada, com a finalidade de atribuir sentido às informações obtidas.

Este artigo encontra-se dividido em 05 (cinco) seções, sendo que a primeira se refere à introdução, a qual apresenta, em linhas gerais, o respectivo Subprojeto PIBID Geografia do CAPF/UERN. Na segunda seção, apresenta-se uma discussão sobre a relação basilar entre as dimensões da formação docente e a formação inicial, a partir dos saberes didáticos e geográficos. A terceira seção é alusiva ao papel do PIBID na formação inicial de professores. A quarta seção assinala a importância do programa no contexto da licenciatura em Geografia, especificamente na conjuntura 
do Subprojeto PIBID Geografia do CAPF/UERN, a partir da visão dos licenciados em Geografia. Por fim, na quinta e última seção, são tecidas algumas considerações finais acerca do estudo.

Este artigo possibilita a compreensão geral da contribuição do referido Subprojeto para a formação inicial de licenciados em Geografia, considerando o arcabouço teórico-prático apreendido durante 04 (quatro) anos de atuação no PIBID (2014-2018).

\section{FORMAÇÃO DOCENTE, FORMAÇÃO INICIAL E SABERES DOCENTES}

A formação docente se constitui como o processo de preparação do professor para exercer a sua profissão. A tarefa de ensinar não é simples, exige o desenvolvimento de competências e habilidades e requer, dos professores, a apreensão de conhecimentos específicos para a prática docente.

Os professores, no exercício de suas funções e na prática da profissão, desenvolvem saberes específicos, que são baseados no trabalho cotidiano e no conhecimento do seu meio, brotam da experiência e são validados, incorporando-se à experiência individual e coletiva, sob a forma de hábitos e de habilidades de saber-fazer e saber-ser (TARDIF, 2011).

Esse processo, repleto de desafios, é substancial para o início da construção da identidade profissional do ser professor, que vai solidificando-se a partir de suas vivências e experiências em: estágios, programas formativos e atividades de intervenção no âmbito escolar. Os saberes dos professores são resultantes de um processo de construção de conhecimentos no decorrer da carreira profissional, na qual o professor aprende, gradativamente, a dominar seu ambiente de trabalho e, quando nele inserido, o interioriza por meio de regras de ação, as quais se tornam parte integrante de sua prática (TARDIF, 2011).

Com efeito, a formação inicial docente é essencial para fortalecer os saberes constitutivos da ciência e estabelecer caminhos para direcionar o agir pedagógico, de modo que fomente a mediação dos saberes disciplinares com significado. Esses saberes alicerçam a prática docente e a formação dos professores da Educação Básica. No entanto, o seu valor dependerá das dificuldades que os professores venham a apresentar em relação à prática docente (PIRES, 2009).

É através do contato direto com o ambiente escolar e das experiências em sala de aula com os sujeitos educativos que o licenciando tem a possibilidade da capacitação prática profissional durante a formação acadêmica, oportunizando integrar os saberes acadêmicos com os saberes 
escolares, o que favorece a construção de possíveis caminhos metodológicos para atribuir sentido à construção dos saberes em sala de aula.

É certo, pois, que o professor, durante as formações inicial e continuada, precisa compreender o próprio processo de construção do conhecimento escolar, entender as diferenças do processo de produção dos saberes científico e escolar, bem como conhecer as características da cultura escolar (PEREIRA, 1999).

Acredita-se que o desafio das universidades na contemporaneidade é assegurar, na base curricular, saberes que auxiliem a formação de sujeitos emancipados. Para tanto, torna-se relevante integrá-los aos saberes científicos, articulando-os com os saberes escolares, para superar a fragmentação e dissociação entre o que se aprende na academia e o que se transpõe para a prática em sala de aula. Assim, concordamos com Pimenta (1999, p. 18), quando a autora diz esperar que a licenciatura possa desenvolver nos alunos "conhecimentos e habilidades, atitudes e valores que lhes possibilitem permanentemente irem construindo seus saberes-fazeres docentes a partir das necessidades e desafios que o ensino como prática social lhes coloca no cotidiano".

Desse modo, os saberes docentes devem ser apreendidos e mobilizados pelos professores de modo que, ao se apropriarem de valores e de conhecimentos disciplinares, criem possibilidades para que os alunos da escola básica produzam seus próprios conhecimentos e os articulem com a realidade à sua volta, estabelecendo significados com aquilo que é estudado.

Decerto, o trabalho docente requer um processo constante de aperfeiçoamento, logo, é preciso que as formações inicial e continuada estejam alinhadas às transformações da sociedade, $o$ que impacta diretamente na produção do conhecimento produzido e, consequentemente, nas metodologias de ensino, que auxiliam na reprodução e mediação deste conhecimento no ambiente escolar. Nesse sentido, Pontuschka, Paganelli e Cacete (2007, p. 95-96) destacam:

\footnotetext{
Assim, sua prática pedagógica requer de si reflexão, crítica e constante criação e recriação do conhecimento e das metodologias de ensino, o que pressupõe uma atividade de investigação permanente que necessita ser apreendida e valorizada. [...]. Nesse sentido, é importante que os professores, em seu processo formativo, sobretudo inicial, pesquisem como são produzidos os conhecimentos por eles ensinados.
}

Coadunando com a visão das autoras, reafirma-se que formação docente é essencial para que o professor conheça as bases epistemológicas da ciência que ele ensina, bem como as metodologias que o auxiliem na mediação de conceitos e teorias, as quais podem viabilizar formas de demonstrar aos alunos que o conhecimento escolar tem significado e pode ser utilizado para entender o que 
acontece no tempo e no espaço. Todavia, para que isso aconteça, conforme realidade da escola, este processo precisa, a priori, ser compreendido pelo professor ao longo da formação inicial.

Na conjuntura das formações inicial e continuada de professores, no ano de 2007, o Governo Federal promulga a Lei $\mathrm{n}^{\mathrm{o}} 11.502$, de julho de 2007, a qual compreende uma pauta da Política Nacional de Formação de Professores:

\begin{abstract}
A Lei no 11.502, de julho de 2007, atribui à Coordenação de Aperfeiçoamento de Pessoal de Nível Superior (CAPES) a responsabilidade pela formação de professores da educação básica - uma prioridade do Ministério da Educação. O objetivo é assegurar a qualidade da formação dos professores que atuarão ou que já estejam em exercício nas escolas públicas, além de integrar a educação básica e superior visando à qualidade do ensino público. A Política Nacional de Formação de Professores tem como objetivo expandir a oferta e melhorar a qualidade nos cursos de formação dos docentes. (BRASIL, PORTAL MEC, 2007).
\end{abstract}

Dessa maneira, surgem os programas formativos direcionados à Educação Básica, os quais objetivam fortalecer a formação de professores e a qualidade da educação no país, conforme assegurado na Lei $\mathrm{n}^{\mathrm{o}}$ 11.502, de julho de 2007, a qual "autoriza a concessão de bolsas de estudo e de pesquisa a participantes de programas de formação inicial e continuada de professores para a educação básica" (BRASIL, Lei no 11.502, de julho de 2007, s.p). Sob a óptica dos programas formativos, enfatiza-se o PIBID, criado a partir da iniciativa de políticas públicas voltadas para a formação docente, com o objetivo de também valorizar os professores da Educação Básica.

De modo específico, o PIBID permite ao licenciando construir experiências no universo da sala de aula, através de sua inserção em escolas da Educação Básica. Este programa promove a aproximação entre escola e academia, corroborando para o rompimento da fragmentação entre estes dois âmbitos, construindo elos articuladores entre a Educação Básica e a Educação Superior, além de contribuir para o fortalecimento da valorização da profissão docente.

$\mathrm{Na}$ escola, os licenciandos bolsistas do PIBID começam a vivenciar os primeiros ensaios da prática profissional, com tarefas diversas, a saber: planejamentos, aulas práticas e teóricas, oficinas pedagógicas, gincanas, atividades lúdicas, aulas de campo e projetos. Esses momentos são cruciais no processo formativo de um professor, pois evidencia o local de trabalho do futuro docente, moldando a sua identidade enquanto profissional (MORAIS; FERREIRA, 2014).

O PIBID oportuniza que, na atuação das práticas desenvolvidas na escola, o licenciando mobilize os diferentes tipos de saberes, dentre eles: o saber constituído na formação inicial, o saber curricular, que é incorporado durante a formação e o saber experiencial, adquirido ao longo do processo de prática de ensino em sala de aula e, ainda, vivenciando a experiência com os sujeitos na 
realização das atividades no espaço escolar, que é preponderante para possibilitar a competência pedagógica na formação do licenciando.

Através do PIBID, a formação inicial do licenciando é fortalecida, atribuindo a oportunidade da integração dos saberes que constroem caminhos para efetivar a construção do perfil docente, tornando-se um contributo em potencial para construir propostas que alicercem o desenvolvimento das aprendizagens acerca da prática docente e contribuam com a aprendizagem de estudantes da Educação Básica.

Este ponto impacta de forma crucial no processo formativo dos licenciandos e nos cursos de formação inicial das universidades brasileiras, pois, rompe com o perfil dos cursos de formação que preconizam apenas o saber disciplinar como o promotor do desenvolvimento do profissional.

\section{O PAPEL DO PIBID NA FORMAÇÃO INICIAL DE PROFESSORES DE GEOGRAFIA DO CAPF/UERN}

O debate acerca da formação de professores vem sendo cada vez mais recorrente nos últimos anos, especialmente em torno das seguintes questões: demanda de profissionais da educação, formação inicial e necessidade de formação continuada. Estas questões surgem por intermédio das reflexões e discussões suscitadas nas Instituições de Ensino Superior (IES), o que vem corroborando com a constituição de programas/projetos de fomento à formação docente inicial, a exemplo do PIBID, que surgiu nesse contexto, no ano de 2007, a partir de edital publicado pelo MEC, caracterizado como um programa de concessão de bolsas de iniciação à docência para alunos de cursos de licenciatura, promovido pela CAPES.

De acordo com a Portaria no 096 de 18 de julho de 2013, documento normativo responsável pela regência do programa durante o período destacado neste estudo, a finalidade do PIBID consiste em "fomentar a iniciação à docência, contribuindo para o aperfeiçoamento da formação de docentes em nível superior e para a melhoria da qualidade da Educação Básica pública brasileira” (BRASIL, PORTARIA Nº 096, DE 18 DE JULHO DE 2013).

Nessa conjuntura, o PIBID tem como foco fortalecer os cursos de licenciatura, através da articulação entre universidade e Educação Básica, ao mesmo tempo em que incentiva e promove a realização de pesquisas na formação de professores. Na prática, as atividades concernentes ao PIBID possuem elementos relativos à elevação da qualidade formativa inicial, ao direcionarem-se tanto à 
dimensão conceitual quanto às atividades de escrita, de linguagem e apresentação oral, podendo contribuir, ainda, com a inclusão de temas sociais relevantes no âmbito da Educação Básica.

O PIBID viabiliza um contato de maior alcance temporal e reflexivo do licenciando com a escola, criando um espaço de interação que possibilita um estreitamento de laços das escolas com as IES. O referido programa de formação docente inicial contribui efetivamente com a formação profissional, a partir da inserção do licenciando nas atividades da escola, possibilitando que estes construam uma concepção crítico-reflexiva sobre a docência, por vivenciarem de forma mais consistente os desafios das escolas públicas, em razão de assumirem o compromisso de dedicar-se ao menos 8 (oito) horas semanais às atividades do PIBID, incluindo os momentos de planejamento e atuação nas escolas parceiras.

O programa tem propiciado uma formação mais prática, na perspectiva pedagógica, uma vez que os licenciandos têm produzido materiais didáticos pedagógicos variados, a exemplo de jogos, mapas, maquetes e vídeos, além de incentivar o uso de espaços escolares, como a biblioteca e o laboratório de informática.

O fato de os licenciandos bolsistas estarem envolvidos diretamente com pesquisas sobre ensino/educação possibilita, por parte deles, a produção de textos científicos que, posteriormente, são socializados em eventos acadêmicos e científicos, bem como em periódicos da área, como forma de divulgar os resultados do programa. Para além disso, podemos salientar, ainda, o papel do PIBID para os professores supervisores escolares, que, ao se envolverem com o projeto, são instigados a um processo de formação continuada e autorreflexiva, por meio da troca de experiências com os licenciandos.

Nesse sentido, a experiência com o PIBID, a partir da inserção do licenciando no ambiente escolar, algumas vezes, antes mesmo do estágio, tende a corroborar com uma ideia de formação mais sólida, pois traz a possibilidade de alguns licenciandos vivenciarem a dinâmica escolar, para além dos componentes curriculares do estágio supervisionado. Tal prerrogativa proporciona-lhes espaço e tempo para refletir sobre as responsabilidades da docência e adquirir meios de aperfeiçoar a formação inicial através de pesquisas desenvolvidas na escola campo de atuação.

Ademais, o PIBID propicia uma maior interação entre teoria e prática na formação docente, que é um dos princípios fundamentais no processo de qualificação profissional. No entanto, dentro das matrizes curriculares dos cursos de licenciatura, essa interação ainda é um desafio, pois aparecem, segundo Pimenta e Lima (2004, p. 34), como "espaços desiguais de poder na estrutura curricular, 
atribuindo-se menor importância à carga horária denominada 'prática"”. Logo, o PIBID vem justamente amenizar essa dicotomia.

O PIBID, enquanto programa formativo, tem se apresentado como um relevante contributo para a formação inicial de professores, uma vez que possibilita aos licenciandos bolsistas construir aprendizagens em torno da formação profissional, mediante articulação entre os conhecimentos científicos, os saberes docentes e os saberes construídos a partir da experiência da prática de ensino em sala de aula.

Sob esse ângulo, vejamos algumas das ações desenvolvidas no âmbito do Subprojeto PIBID Geografia do CAPF/UERN (Quadro 01), especificadamente no curso Licenciatura Plena em Geografia, intitulado "Conhecimento Didático e Conhecimento Geográfico: diálogos entre saberes na/com a comunidade escolar para a formação do licenciando em Geografia".

\section{QUADRO 01: SUBPROJETO PIBID GEOGRAFIA DO CAPF/UERN}

\begin{tabular}{|c|c|}
\hline \multicolumn{2}{|c|}{ Ações do Subprojeto PIBID Geografia - no quadriênio 2014-2018 } \\
\hline Nome da Ação & Descrição \\
\hline $\begin{array}{l}\text { Sensibilização e } \\
\text { mobilização }\end{array}$ & $\begin{array}{l}\text { Esta ação tinha como objetivo estabelecer os primeiros contatos entre Universidade } \\
\text { e Escola, através da apresentação do programa de formação docente inicial e do } \\
\text { Subprojeto PIBID Geografia à comunidade escolar, pelos bolsistas e professores } \\
\text { supervisores. }\end{array}$ \\
\hline $\begin{array}{l}\text { Diagnóstico Sobre o } \\
\text { Ensino de Geografia }\end{array}$ & $\begin{array}{l}\text { Viabilizava a construção de um diagnóstico sobre o ensino de Geografia na Escola } \\
\text { parceira, juntamente com os professores supervisores que exerciam o papel de } \\
\text { articuladores durante a construção da leitura diagnóstica. }\end{array}$ \\
\hline $\begin{array}{l}\text { Elaboração de Planos } \\
\text { Semestrais de Trabalho } \\
\text { Docente }\end{array}$ & $\begin{array}{l}\text { O planejamento pedagógico era realizado com base no diagnóstico sobre o ensino } \\
\text { de Geografia, desenvolvido através da organização e definição das atividades para } \\
\text { o ano letivo. Basicamente era um plano de trabalho semestral construído por } \\
\text { professores supervisores e bolsistas, com definição de conteúdo, objetivos, } \\
\text { dinâmicas e atividades. }\end{array}$ \\
\hline $\begin{array}{l}\text { Nivelamento teórico- } \\
\text { conceitual e metodológico } \\
\text { sobre a formação docente } \\
\text { para a Educação Básica e } \\
\text { prática de ensino de } \\
\text { Geografia }\end{array}$ & $\begin{array}{l}\text { Esta ação acontecia no formato de "Curso de nivelamento teórico-conceitual e } \\
\text { metodológico" entre o coordenador do Subprojeto, licenciandos bolsistas e } \\
\text { professores supervisores. Através da discussão de textos em torno da temática da } \\
\text { educação básica e da socialização de experiências, a atividade promovia a reflexão } \\
\text { em volta dos desafios e perspectivas que perpassam a educação. }\end{array}$ \\
\hline $\begin{array}{l}\text { Elaboração de minicursos } \\
\text { e oficinas didático- } \\
\text { pedagógicas diretamente } \\
\text { nas escolas parceiras }\end{array}$ & $\begin{array}{l}\text { Tendo em vista que um dos objetivos do PIBID é inserir os licenciandos no cotidiano } \\
\text { escolar, oportunizando-lhes a vivência com a criação e a mediação de metodologias } \\
\text { de ensino-aprendizagem, as oficinas e minicursos eram estratégias desenvolvidas } \\
\text { com objetivo de diversificar as práticas de ensino de Geografia. }\end{array}$ \\
\hline $\begin{array}{l}\text { Incentivo à produção e } \\
\text { publicação de relatos de } \\
\text { experiência - Participação } \\
\text { em eventos }\end{array}$ & $\begin{array}{l}\text { Ação que tinha como foco o incentivo à pesquisa na formação de professores e à } \\
\text { socialização de experiências sobre as práticas de ensino desenvolvidas no contexto } \\
\text { do Subprojeto PIBID Geografia, para serem partilhados em eventos acadêmicos } \\
\text { científicos. }\end{array}$ \\
\hline
\end{tabular}

Fonte: Dados organizados pelos(as) autores(as) a partir do Subprojeto PIBID Geografia (2014-2018). 
O Subprojeto PIBID Geografia foi idealizado com o objetivo de proporcionar aos licenciandos do Curso de Geografia uma interação entre os saberes acadêmicos e os saberes escolares, tendo como foco um processo de ensino-aprendizagem dinâmico no Ensino Fundamental e no Ensino Médio.

As escolas parceiras estão localizadas no semiárido nordestino, especificadamente no município de Pau dos Ferros, situado na região Oeste Potiguar do Estado do Rio Grande do Norte, e atendem alunos oriundos dos diversos bairros da zona urbana, assim como de comunidades da zona rural e de municípios vizinhos.

Alinhado à proposta de fortalecimento da escola pública enquanto espaço de formação de professores, o Subprojeto PIBID Geografia, por meio de suas ações, busca diversificar o processo de ensino-aprendizagem, a partir de práticas que oportunizem a construção de conhecimentos geográficos e possam subsidiar a leitura do espaço geográfico e das transformações sociais, políticas, econômicas e ambientais que nele se desdobram.

Nesse viés, opta-se por compartilhar a experiência de licenciados em Geografia, bolsistas egressos do Subprojeto supracitado, no que diz respeito à dinâmica de construção de conhecimentos no processo de formação docente. Para tanto, tomamos como parâmetro as experiências vivenciadas pelos bolsistas ao longo do quadriênio 2014-2018. Nesse seguimento, apresenta-se o olhar dos licenciados sobre as contribuições do PIBID para a formação docente em Geografia, com base nas suas experiências vivenciadas ao longo do período de atuação no Subprojeto Geografia.

\section{METODOLOGIA}

Com o objetivo de analisar as contribuições do PIBID e do Subprojeto Geografia para a formação de professores desta área, tendo como colaboradores quatro egressos do CAPF/UERN, sistematizamos a construção dos dados empíricos a partir dos seus relatos de experiências enquanto bolsistas do programa de iniciação à docência.

O caminho teórico-metodológico delineado para esta pesquisa consiste em uma abordagem qualitativa, com uso de pesquisa bibliográfica, por meio da qual fundamenta-se as discussões teóricas tecidas no estudo, combinando com uso de entrevistas semiestruturadas com questões abertas, as quais são analisadas à luz da Análise de Conteúdo (AC).

O roteiro de questões para a entrevista semiestruturada foi idealizado a partir da trajetória das vivências dos sujeitos no PIBID, com intuito de dar visibilidade ao conhecimento que os bolsistas 
egressos, atualmente Professores de Geografia, construíram sobre a aprendizagem da docência, ao longo da formação inicial. As respostas foram gravadas com uso da ferramenta gravador de voz do telefone móvel e, posteriormente, sistematizadas para análise.

A AC foi uma técnica de grande utilidade para a interpretação dos dados construídos nesta pesquisa, por meio da qual procurou-se extrair os significados das falas evidenciadas na entrevista. A AC está fundamentada nas discussões de Oliveira et al. (2003), utilizando as seguintes etapas: i) organização do material de trabalho, que neste caso são as falas transcritas dos(as) colaboradores(as), as quais foram sistematizadas em arquivo no processador de textos Microsoft Word; ii) definição das unidades de registros, constituídas por palavras e/ou conjunto de palavras; iii) definiç̧ão de categorias; e iv) interpretação das falas e discussão dos principais achados.

As categorias elencadas foram definidas através do agrupamento das perguntas e respostas da entrevista e à medida que realizou-se as leituras e o processo de tratamento dos dados: 1) Formação profissional, 2) Contribuições do PIBID para a Educação Básica; e 3) Experiência com os Miniprojetos.

O estudo teve como colaboradores(as) quatro (4) egressos do curso de Licenciatura em Geografia do CAPF/UERN. A escolha deu-se mediante o seguinte critério: estar, atualmente, atuando como docente de Geografia. Com vistas à preservação da identidade dos(as) colaboradores(as) da pesquisa, tais sujeitos são identificados através de representações alfanumérica: Colaborador(a) 1, Colaborador(a) 2, Colaborador(a) 3 e Colaborador(a) 4.

\section{RESULTADOS E DISCUSSÕES}

\section{O PIBID e o subprojeto Geografia sob o olhar dos protagonistas}

Com base nas leituras e nos tratamentos dos dados, define-se um conjunto com três categorias analíticas, de acordo com temas/tópicos que dialogam com a temática da pesquisa: 1) Formação profissional; 2) Contribuições do PIBID para a Educação Básica; e 3) Experiência com os Miniprojetos.

Assim, a apresentação dos resultados da pesquisa está organizada nos quadros seguintes, por meio dos quais é possível elencar elementos significativos relativos à contribuição do Subprojeto PIBID Geografia do CAPF/UERN para a formação de professores. 
Para melhor compreender a contribuição do PIBID para os licenciados em Geografia, são apresentadas a categoria formação profissional e as respostas dos (as) colaboradores(as) mediante a primeira indagação realizada durante a entrevista (Quadro 02).

QUADRO 02: FORMAÇÃO PROFISSIONAL

\begin{tabular}{|c|c|c|}
\hline \multicolumn{2}{|c|}{ Categoria } & Unidade de Registro \\
\hline \multicolumn{2}{|c|}{ Formação profissional } & $\begin{array}{l}\text { Formação docente; conhecimento teórico-prático; prática } \\
\text { docente; construção; reflexão. }\end{array}$ \\
\hline \multicolumn{3}{|c|}{ Qual a contribuição do PIBID para a sua formação profissional? } \\
\hline COLABORADOR(A) 1 & $\begin{array}{l}\text { "O P } \\
\text { que } \\
\text { escol } \\
\text { instrt } \\
\text { confi } \\
\text { contr } \\
\text { e par }\end{array}$ & $\begin{array}{l}\text { experiência valiosa para minha formação profissional, ao ponto } \\
\text { onou adquirir conhecimentos teórico-práticos da realidade } \\
\text { rrer da minha formação profissional, configurou-se como } \\
\text { onstrução, reprodução e reflexão das práticas docentes. O } \\
\text { om a realidade escolar, no qual estive presente nesse período, } \\
\text { la significativa para o meu amadurecimento prático-conceitual } \\
\text { das ações pedagógicas". }\end{array}$ \\
\hline COLABORADOR(A) 2 & $\begin{array}{l}\text { "Acr } \\
\text { opor } \\
\text { licen } \\
\text { nece }\end{array}$ & $\begin{array}{l}\text { PIBID foi um programa de excelência para quem teve } \\
\text { er integrante. Porque facilitou e intensificou o contato dos } \\
\text { a sala de aula, ao mesmo tempo em que nos atentou para a } \\
\text { letirmos sobre a formação docente". }\end{array}$ \\
\hline COLABORADOR(A) 3 & $\begin{array}{l}\text { "Cre } \\
\text { da } f \\
\text { form } \\
\text { expe } \\
\text { enori } \\
\text { acerc } \\
\text { cons } \\
\text { form } \\
\text { ativi }\end{array}$ & $\begin{array}{l}\text { consegue dar respostas significativas para elevar a qualidade } \\
\text { al dos professores, à medida que promove integração dos } \\
\text { futuro ambiente de trabalho. Isso é fantástico. Para mim, as } \\
\text { nciadas enquanto PIBIDIANO(A) foram de uma riqueza } \\
\text { ibilidade de trocas de saberes e construção de conhecimento } \\
\text { os que caracterizam a nossa profissão. A partir do programa, } \\
\text { der que os conhecimentos adquiridos durante o processo de } \\
\text { tado, corroboram, em particular, para a construção de minha } \\
\text { rofissional, sem dúvidas". }\end{array}$ \\
\hline COLABORADOR(A) 4 & $\begin{array}{l}\text { "As } \\
\text { minh } \\
\text { além } \\
\text { um c } \\
\text { prop } \\
\text { e col } \\
\text { socie }\end{array}$ & $\begin{array}{l}\text { lvidas durante o projeto tiveram grande relevância para a } \\
\text { cente, proporcionando uma maior aproximação com a escola, } \\
\text { ar para enfrentar situações diversas do universo escolar, com } \\
\text { duro. Apesar de todas as dificuldades, o PIBID também me } \\
\text { eflexão em torno de como pretendo atuar enquanto professora, } \\
\text { r o diferencial através das aulas, para a construção de uma } \\
\text { com cidadãos críticos e participativos". }\end{array}$ \\
\hline
\end{tabular}

Fonte: Dados da pesquisa, 2020.

Entendendo a formação profissional de professores como um conjunto de conhecimentos teórico-práticos, de habilidades e competências, baseada em um processo contínuo de construção de saberes e alicerçado em experiências e ações cotidianas, buscamos entender, sob o olhar dos sujeitos que participaram do programa formativo, como o PIBID corrobora com a formação profissional.

Diante das falas apresentadas anteriormente, pode-se evidenciar que o PIBID se constitui como um espaço formativo que possibilita a superação da dicotomia teoria versus prática, através da 
aproximação dos licenciandos com o ambiente escolar. A experiência com a docência, construída a partir da vivência na escola, potencializa nos licenciandos o reconhecimento da necessidade de pensar o processo formativo inicial, de maneira mais consistente e reflexiva.

Com efeito, nota-se que o olhar dos(as) colaboradores(as) sobre o programa revela a importância das escolas atuarem como espaços formativos, tendo em vista que, isto favorece uma maior aproximação com as diversas realidades que caracterizam a profissão docente. É certo, pois, que a formação docente inicial, através do PIBID e alicerçada na vivência dos espaços das escolas parceiras, oportuniza aos bolsistas a compreensão de que a formação docente se dá através de um processo contínuo de saberes que engloba conhecimentos científicos, conhecimentos didáticopedagógicos e conhecimentos construídos a partir das experiências adquiridas no âmbito da escola básica.

Desse modo, o PIBID volta-se para possibilitar a imersão do licenciando bolsista no ambiente de trabalho, o que lhe permite adquirir, produzir e construir saberes necessários ao trabalho docente.

Uma das perspectivas desta pesquisa é também identificar as contribuições do PIBID para a Educação Básica, posto que este é caracterizado como um programa formativo que tem a escola como campo de atuação, estudo e pesquisa. Relativo a isso, no Quadro 03, estão dispostas as respostas dos(as) colaboradores(as) a respeito das contribuições do PIBID para as escolas parceiras do Subprojeto Geografia.

QUADRO 03: CONTRIBUIÇÕES DO PIBID PARA A EDUCAÇÃO BÁSICA

\begin{tabular}{|c|c|c|}
\hline \multicolumn{2}{|c|}{ Categoria } & Unidade de Registro \\
\hline \multicolumn{2}{|c|}{ Contribuições do PIBID para a Educação Básica } & $\begin{array}{l}\text { Apoio; parceria entre escola e universidade; } \\
\text { atividades; aprendizado dos alunos. }\end{array}$ \\
\hline \multicolumn{3}{|c|}{ Qual a contribuição do PIBID para a escola parceira do Subprojeto Geografia? } \\
\hline COLABORADOR(A) 1 & \multicolumn{2}{|c|}{$\begin{array}{l}\text { "O PIBID tem como como um dos objetivos fortalecer a parceria entre a } \\
\text { Universidade e as escolas púbicas, parceria essa responsável por atribuir } \\
\text { soluções educativas para diversos problemas ocorrentes no universo escolar. } \\
\text { Dessa forma, as atividades desenvolvidas no projeto ajudam as escolas a } \\
\text { enfrentarem os problemas educacionais, valorizando e engrandecendo o } \\
\text { processo de ensino-aprendizagem". }\end{array}$} \\
\hline COLABORADOR(A) 2 & \multicolumn{2}{|c|}{$\begin{array}{l}\text { "Acredito que para a escola onde atuei foi riquíssimo, visto que a instituição } \\
\text { sempre esteve disposta a dialogar com os Pibidianos sobre as propostas de } \\
\text { intervenção, pois compreendia que o programa estava lá para contribuir. E } \\
\text { até hoje, a escola onde atuei fala muito bem desses projetos que recebeu } \\
\text { entre os anos de } 2014 \text { e 2018, assim como dos bolsistas licenciandos". }\end{array}$} \\
\hline
\end{tabular}

Nonato e et al, 2021

ISSN 2594-9616 


\begin{tabular}{|c|c|}
\hline COLABORADOR(A) 3 & $\begin{array}{l}\text { "Possibilidades de atividades. Essa, para mim, é uma contribuição fabulosa. } \\
\text { Via, no tempo em que atuei, vários bolsistas movimentando as aulas, os } \\
\text { alunos, as formas de aprender, construindo possiblidades para a escola. O } \\
\text { Pibidiano qualifica melhor sua formação e os alunos da escola ganham com } \\
\text { a diversidade de possibilidades de aprender. O PIBID só tem, sem dúvidas, } \\
\text { a contribuir com a educação". }\end{array}$ \\
\hline COLABORADOR(A) 4 & $\begin{array}{l}\text { "Como sabemos, a carga horária dos professores é bastante extensa, com } \\
\text { isso, muitos não conseguem ou não têm tempo suficiente para planejar } \\
\text { atividades diferenciadas e dinâmicas para seus alunos. Assim, o PIBID } \\
\text { insere-se como uma importante ferramenta de apoio, através dos bolsistas } \\
\text { que, em parceria com os professores supervisores, buscam constantemente } \\
\text { realizar atividades didático-pedagógicas dinâmicas, como também projetos } \\
\text { que auxiliem e potencializem o aprendizado dos alunos". }\end{array}$ \\
\hline
\end{tabular}

Fonte: Dados de pesquisa, 2020.

Como pode ser visto, as falas dos(as) colaboradores(as) indicam que as atividades desenvolvidas pelo PIBID ajudam a atribuir soluções educativas para problemas educacionais, a partir da cooperação dos licenciandos bolsistas com propostas de intervenção que movimentam e dinamizam o processo de ensino-aprendizagem nas escolas parceiras. Desse modo, compreende-se o PIBID como uma experiência de excelência na formação de professores, tanto na perspectiva da construção de experiências quanto da inserção e da prática docente nas escolas.

$\mathrm{O}$ (a) Colaborador(a) 3 sinaliza que os diálogos estabelecidos com a escola parceira, em volta das propostas de intervenções realizadas, impulsionaram o reconhecimento do programa dentro da instituição de ensino, uma vez que, segundo ele(a), “[...] até hoje a escola parceira destaca a relevância das ações desenvolvidas pelos bolsistas do Subprojeto Geografia no quadriênio 2014/2018”.

As falas demonstram que o PIBID fortalece a parceria entre professores supervisores e licenciandos, em razão do trabalho em conjunto, o que oportuniza também a valorização da formação inicial e da formação continuada de professores, mediante troca de saberes e propostas didáticas.

Assim, é nesse panorama de mobilização de sujeitos, licenciandos, alunos e professores supervisores que o PIBID vem construindo relações entre a universidade e a escola básica e consolidando-se como uma política de formação concreta e viável.

No intuito de ressaltar as atividades desenvolvidas pelo Subprojeto PIBID Geografia do CAPF/UERN, definimos as categorias Subprojeto PIBID e Experiência com os Miniprojetos, através das quais apresentam-se as ações realizadas e as experiências vivenciadas pelos licenciandos bolsistas, no âmbito dos Miniprojetos, entre os anos de 2014 e 2018 (Quadro 04). 
QUADRO 04: SUBPROJETO PIBID E EXPERIÊNCIA COM OS MINIPROJETOS

\begin{tabular}{|c|c|c|}
\hline \multicolumn{2}{|c|}{ Categoria } & Unidade de Registro \\
\hline \multicolumn{2}{|c|}{ Experiência com os Miniprojetos } & $\begin{array}{l}\text { Alunos; divulgar; auxiliar; aprendizagem significativa; } \\
\text { protagonismo; experiências exitosas; olhar maduro; } \\
\text { atuação docente. }\end{array}$ \\
\hline \multicolumn{3}{|c|}{ Descreva os objetivos das ações realizadas no âmbito do Miniprojeto sob o qual você participou. } \\
\hline SUJEITOS & $\begin{array}{c}\text { NOME DO } \\
\text { MINIPROJETO }\end{array}$ & OBJETIVOS \\
\hline COLABORADOR(A) 1 & Rádio Escola & $\begin{array}{l}\text { "Divulgar as atividades do PIBID; promover um } \\
\text { momento de descontração nos intervalos, através de } \\
\text { música e de atividades lúdicas; desenvolver habilidades } \\
\text { e tendências comunicacionais nos alunos da Educação } \\
\text { Básica; instrumentalizar a rádio como espaço para } \\
\text { debater temas transversais e divulgar eventos e } \\
\text { atividades da escola". }\end{array}$ \\
\hline COLABORADOR(A) 2 & Projeto ENEM & $\begin{array}{l}\text { "Auxiliar os alunos que estavam em processo de } \\
\text { finalização da terceira série na realização das provas do } \\
\text { ENEM". }\end{array}$ \\
\hline COLABORADOR(A) 3 & Jornal Escola & $\begin{array}{l}\text { "Divulgar informações e notícias que pudessem ser } \\
\text { construtivas para a comunidade escolar, sendo que os } \\
\text { alunos eram nosso foco, tendo como objetivos } \\
\text { específicos: planejar edições do jornal; selecionar } \\
\text { informaçoes; escrever e publicar textos". }\end{array}$ \\
\hline COLABORADOR(A) 4 & $\begin{array}{l}\text { Projeto Artístico } \\
\text { Cultural }\end{array}$ & $\begin{array}{l}\text { "Construir com os alunos uma aprendizagem } \\
\text { significativa a respeito da região Nordeste e das } \\
\text { diferentes paisagens que a compõem". }\end{array}$ \\
\hline \multicolumn{3}{|c|}{ Qual o impacto da experiência dos Miniprojetos na ação docente? } \\
\hline COLABORADOR(A) 1 & \multicolumn{2}{|c|}{$\begin{array}{l}\text { "As ações pedagógicas apresentadas no projeto são de fundamental } \\
\text { importância para a formação profissional e pessoal, já que nos tornamos } \\
\text { pessoas mais responsáveis no ambiente escolar". }\end{array}$} \\
\hline COLABORADOR(A) 2 & \multicolumn{2}{|c|}{$\begin{array}{l}\text { "Riquíssimo, pois nunca tinha trabalhado com essa questão dos aulões, que é } \\
\text { uma dinâmica diferente da sala de aula. A gente assumia o protagonismo da } \\
\text { prática docente, ministrando aulas para os alunos sobre temas específicos de } \\
\text { Geografia para o ENEM. E isso fez com que nós pudéssemos estudar mais, } \\
\text { para estarmos mais qualificados para auxiliar os alunos. Então, o Subprojeto } \\
\text { PIBID Geografia proporcionou uma experiência enriquecedora, a partir da } \\
\text { desenvoltura de projetos que possibilitam experiências exitosas e traçam outros } \\
\text { caminhos para a escola básica, como no caso dos aulões do Projeto ENEM". }\end{array}$} \\
\hline COLABORADOR(A) 3 & \multicolumn{2}{|c|}{$\begin{array}{l}\text { "O PIBID me preparou para enfrentar as mais difíceis situações com um olhar } \\
\text { mais maduro. Me levou a momentos de reflexão entorno da minha atuação } \\
\text { enquanto professor e de como posso fazer o diferencial, através das aulas, para } \\
\text { a construção de uma sociedade melhor, com cidadãos críticos e participativos". }\end{array}$} \\
\hline COLABORADOR(A) 4 & \multicolumn{2}{|c|}{$\begin{array}{l}\text { "Essa experiência foi bastante desafiadora, principalmente diante das } \\
\text { dificuldades encontradas, sobretudo no que diz respeito aos recursos, como } \\
\text { caixa de som para os ensaios e os figurinos. Exigiu também bastante paciência } \\
\text { e dedicacãa, pois foram várias semanas de preparação. No entanto, ao finalizar } \\
\text { a atividade, foi muito gratificante em ver que, mesmo com todas as } \\
\text { dificuldades, deu tudo certo e os alunos e professor supervisor ficaram muito } \\
\text { satisfeitos. Assim, essa atividade impactou de maneira positiva, pois pude }\end{array}$} \\
\hline
\end{tabular}




\begin{tabular}{|l|l|}
\hline & $\begin{array}{l}\text { perceber que a atuação docente sempre vai ser desafiadora e é preciso buscar } \\
\text { alternativas para solucionar as situações que se apresentam no cotidiano } \\
\text { escolar". }\end{array}$ \\
\hline
\end{tabular}

Fonte: Dados da pesquisa, 2020.

Como apontado anteriormente, entre as ações definidas no Subprojeto Geografia, tem-se a "elaboração de minicursos e oficinas didático-pedagógicas", que se desdobram em planejamentos mais específicos, em atividades e em projetos. Nesse ínterim, temos os Miniprojetos: propostas que não têm como foco uma abrangência no âmbito da escola inteira, mas sim a uma turma ou grupo de alunos.

Como identificado no quadro acima, ao longo dos anos de 2014 e 2018, foram realizados quatro Miniprojetos nas duas escolas parceiras do Subprojeto Geografia, sendo eles: Rádio Escola, Projeto ENEM, Jornal Escola e Projeto Artístico Cultural. Cada Miniprojeto utiliza-se de uma linguagem particular e possui objetivos específicos, aos quais desdobram-se em intervenções nas escolas.

A proposta da Rádio Escola surge com a finalidade de movimentar as escolas nos momentos de intervalo, a partir de um espaço em que os alunos pudessem ser protagonistas e desenvolver habilidades e competências artísticas de comunicação.

O Projeto ENEM oportunizava aulões para o Exame Nacional do Ensino Médio, com foco nos principais conteúdos de Geografia abordados na prova. Trata-se de uma ação que beneficiava tanto os licenciandos bolsistas, que assumiam o protagonismo da mediação de conteúdos, quanto os alunos que tinham a oportunidade de ter uma formação mais direcionada para o ENEM. Neste ponto, percebe-se como o PIBID, de fato, contribui para formação de professores, assim como para a formação dos alunos da Educação Básica.

O Jornal Escola tinha como foco estabelecer um veículo de circulação de informação nas escolas. Desse modo, as edições eram montadas em parceria com bolsistas do PIBID Geografia, alunos e professores supervisores. Cada edição era constituída por uma seção com um assunto principal, seguido de assuntos secundários, com dicas de leitura, curiosidades e atualidades locais e globais.

Por fim, o Projeto Artístico Cultural tinha como foco trabalhar a linguagem teatral como recurso mediador da aprendizagem de conteúdos sobre a região Nordeste. Para tanto, foram trabalhados elementos referentes ao processo de montagem de um espetáculo teatral, a saber: a leitura do texto, a definição de personagens, o ensaio da coreografia de dança, marcação de cenas, voz, corpo 
e desenvoltura dos alunos ao longo dos ensaios. A culminância do projeto ocorreu com a apresentação do espetáculo teatral no pátio da escola.

Mediante tais observações, ressaltamos o contato dos bolsistas do Subprojeto PIBID Geografia com diferentes linguagens no ensino básico durante a formação inicial, que corrobora com a inserção de metodologias diversas no ambiente educacional. Esse tipo de ação exigiu dos bolsistas a busca por referenciais, leitura, reflexão e elaboração de propostas que proporcionassem os alunos ampliar seus modos de aprender.

Ainda no tocante à categoria Experiência com os Miniprojetos, procurou-se averiguar o impacto desta experiência na ação docente. Desse modo, as falas indicam experiências exitosas para a formação profissional a partir do protagonismo da ação docente. Percebe-se, pois, que o impacto dos Miniprojetos na ação docente dos bolsistas foi relevante e que suscitou reflexões, da fase inicial (planejamento), passando pelos desafios do desenvolvimento, até chegar na execução/finalização.

Nota-se, ainda, a partir da fala dos(as) colaboradores(as), as possibilidades que o PIBID traz de expandir o horizonte, no que diz respeito à adoção de metodologias, oriundas do planejamento e da elaboração de materiais e estratégias didáticos-pedagógicos. É notável, portanto, que essas ações promovem contribuições para os sujeitos envolvidos (bolsistas, professores supervisores e alunos).

Decerto, a análise das respostas dos(as) colaboradores(as) permitem reafirmar que, ao longo do processo de inserção dos licenciandos bolsistas nas escolas parceiras, o PIBID tem contribuído para o aperfeiçoamento da formação inicial de professores de diferentes maneiras, seja pela vivência prolongada com o ambiente escolar, pelas abordagens de materiais didáticos, pela mediação de projetos e até mesmo pela socialização dessas experiências na universidade. Da mesma forma, o programa também colabora com as escolas parceiras e com o processo de ensino-aprendizagem, à medida que procura envolver os alunos como sujeitos ativos do referido processo.

\section{CONSIDERAÇÕES FINAIS}

A inserção dos professores em formação inicial, no futuro espaço de atuação profissional, contribui para o fortalecimento da identidade docente, favorecendo o desenvolvimento das competências pedagógicas, por intermédio da vivência no ambiente escolar, além de possibilitar-lhes conhecer o cotidiano da escola e do trabalho docente. Tal experiência, oportuniza que o professor em formação inicial articule os saberes acadêmicos com os saberes escolares e construa estratégias metodológicas para viabilizar a mediação dos conhecimentos na Educação Básica. 
As ações dos Miniprojetos - Projeto ENEM, Rádio Escola, Jornal Escola e Projeto Artístico Cultural - favoreceram momentos significativos para a formação dos licenciandos bolsistas, que atuaram como protagonistas no desenvolvimento dos projetos nas escolas parceiras.

As experiências formativas apresentadas delineiam as práticas pedagógicas/educativas desenvolvidas no âmbito do Subprojeto "Conhecimento Didático e Conhecimento Geográfico: diálogos entre saberes na/com a comunidade escolar para a formação do licenciando em Geografia”. Assim, os saberes adquiridos são ressignificados para o exercício da docência, a partir dos subsídios das ações do PIBID Geografia, fundamentadas em diferentes linguagens para os alunos da Educação Básica.

O resultado das ações apresentadas é satisfatório, pois, permite aos envolvidos estabelecer relações entre escola e comunidade, indivíduo e sociedade e escola e universidade, interações basilares na compreensão e construção do ser professor na Educação Básica.

De modo especial, o subprojeto abre novas perspectivas para os licenciandos refletirem sobre o papel social que o educador deve assumir enquanto ser intelectual e sujeito social na sociedade contemporânea. Dessa forma, contribuindo com a formação de professores que conhecem a realidade da escola básica e vivenciaram os reais problemas que fazem parte deste ambiente, cotidianamente. Sendo assim, ao serem inseridos neste espaço, na função de professores, terão mais chances de ter uma postura mais preparada para lidar com os desafios e proposições que emergem no exercício docente.

\section{REFERÊNCIAS}

BRASIL. Lei $\mathbf{N}^{\mathbf{0}}$ 11.502, de 11 de julho de 2007. Modifica as competências e a estrutura organizacional da fundação Coordenação de Aperfeiçoamento de Pessoal de Nível Superior - CAPES e autoriza a concessão de bolsas de estudo e de pesquisa a participantes de programas de formação inicial e continuada de professores para a educação básica. Brasília, 11 de julho de 2007; Presidência da República, Casa Civil, Subchefia para Assuntos Jurídicos. Disponível em: http://www.planalto.gov.br/ccivil_03/_Ato2007-2010/2007/Lei/L11502.htm. Acesso em 12 jun. 2020.

BRASIL. Portaria n ${ }^{\circ}$ 096, de 18 de julho de 2013. Normas do Programa Institucional de Bolsa de Iniciação à Docência. Diário Oficial da União, Brasília, 23 de julho de 2013. Disponível em: http://www.jusbrasil.com.br/diarios/56897963/dou-secao-1-23-07-2013-pg-11. Acesso em: 28 mar. 2019.

CAVALCANTI, L. de S. Propostas curriculares de Geografia no ensino: algumas referências de análise. Terra Livre, São Paulo, v. 14, 1999, p. 111-128. Disponível em: 
https://www.agb.org.br/publicacoes/index.php/terralivre/article/view/377/359.

Acesso em: 18 mar. 2020.

MORAIS, J. K. C.; FERREIRA, M. A. dos S. Profissionalização docente: construindo saberes a partir da prática no PIBID. HOLOS, Ano 30, Vol. 5, 2014. Disponível em: http://www2.ifrn.edu.br/ojs/index.php/HOLOS/article/view/2096. Acesso em 12 dez. 2019.

OLIVEIRA, E. de et al. Análise de Conteúdo e pesquisa na área da Educação. Revista Diálogo Educacional, Paraná, vol. 4, n. 9, mai. lago., 2003, p. 1-17. Disponível em: https://periodicos.pucpr.br/index.php/dialogoeducacional/article/view/6479. Acesso em: 12 Jan. 2019.

PEREIRA, D. A dimensão pedagógica na formação do geógrafo. Revista AlfaGEO, v.1, n.1, São Paulo, mai. $1999 . \quad$ Disponível em: https://www.agb.org.br/publicacoes/index.php/terralivre/article/view/373/355. Acesso em 12 nov. 2019.

PIMENTA, S. G. e LIMA, M. S. L. Estágio e Docência. São Paulo: Cortez, 2004.

PIMENTA, S. G. Formação de professores: identidade e saberes da docência. In: PIMENTA, S. G. (Org.). Saberes pedagógicos e atividade docente. São Paulo: Cortez Editora, p.15-34.1999.

PIRES, L. M. A Prática Pedagógica do Professor de Geografia no Ensino Fundamental. Dissertação (Mestrado em Geografia). Universidade Federal de Goiás. Instituto de Estudos SócioAmbientais, Programa de Pesquisa e Pós-Graduação em Geografia. Goiânia, 2009.

PONTUSCHKA, N. N. “A formação geográfica e pedagógica do professor”. In: SILVA, J. B. da et al. (orgs.). Panorama da Geografia Brasileira II. São Paulo: Annablume, 2006, p.269-279.

PONTUSCHKA, N. N.; PAGANELli, T. I.; CACETE, N. H. Para Ensinar e Aprender Geografia. São Paulo, Cortez, 2007.

TARDIF, M. Saberes docentes e formação profissional. Ed. 12, Petrópolis, Vozes, 2011. 